Technological University Dublin

DÜBLIN

ARROW@TU Dublin

2013

\title{
Sources of Customer Role Learning During Self-Service Technology Encounters
}

Jennifer Lawlor

Technological University Dublin, jennifer.lawlor@tudublin.ie

Petranka Kelly

Technological University Dublin, petranka15@gmail.com

Michael Mulvey

Technological University Dublin

Follow this and additional works at: https://arrow.tudublin.ie/tfschhmtcon

\section{Recommended Citation}

Kelly, P., Lawlor, J.\& Mulvey, M. (2013) Sources of Customer Role Learning During Self-Service Technology Encounters in Cantoni, L. and Xiang, Z. (Eds) Information and Communication Technologies in Tourism 2013, , Berlin-Heidelberg: Springer.

This Other is brought to you for free and open access by the School of Tourism \& Hospitality Management at ARROW@TU Dublin. It has been accepted for inclusion in Other resources by an authorized administrator of ARROW@TU Dublin. For more information, please contact arrow.admin@tudublin.ie, aisling.coyne@tudublin.ie,gerard.connolly@tudublin.ie.

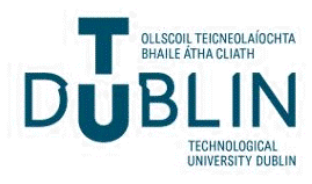




\title{
To be cited as:
}

Kelly, P., Lawlor, J. and Mulvey, M. (2013) Sources of Customer Role Learning During Self-Service Technology Encounters in Cantoni, L. and Xiang, Z. (Eds) Information and Communication Technologies in Tourism 2013 , Berlin-Heidelberg: Springer.

\section{Sources of Customer Role Learning During Self-Service Technology Encounters}

\begin{abstract}
The advance of self-service technologies (SSTs) in the tourism industry has highlighted the role of the customer as co-producer during service encounters. Customer usage of SSTs requires that they have acquired the needed skills and knowledge towards operating the SST efficiently. Despite the recognition of the importance of customer role clarity and ability for successful SST encounters, there is a dearth of knowledge into the process of customer SST role learning. Therefore, this research contributes to knowledge by exploring the sources of customer SST role learning and how customers learn from them. The employed research method is short interviews with airline passengers at an international airport. The results identify six sources of customer learning, namely the SST interface, other customers, company employees, mass media and service environment, negative service outcomes and the customer's workplace.
\end{abstract}

Keywords: self-service technologies; customer roles; customer learning; customer participation

\section{Introduction}

The rapid development of technology in the past decade has been paralleled by the infusion of technology in services and particularly self-service technologies (Castro, Atkinson \& Ezell, 2010). The term 'self-service technologies' (SSTs) is defined by Meuter, Ostrom, Roundtree \& Bitner (2000, p.50) as 'technological interfaces that enable customers to produce a service independent of direct service employee involvement'. Examples of SSTs include online reservation web sites, online banking, kiosk technologies at airports and train stations, retail self check-outs in shops and mobile telephone service applications. This customer service production presupposes the requirement of the appropriate skills and knowledge on the part of the customer to operate the SST (Walker \& Johnson, 2006). Therefore, the aim of this paper is to explore the sources of customer role learning in SST encounters. The employed research method was short interviews with 133 passengers at an international airport. The analysis revealed six sources of customer learning, which are discussed in light of the way customers utilise them in shaping their production role during SST encounters. Those sources of customer learning include the SST interface, other customers, company employees, mass media and the service environment, negative service outcomes and the customer's workplace. The paper concludes with the limitations and suggestions for further research. 


\section{Literature Review}

When companies manage to engage customers in service production in an efficient manner, this may bring significant savings in production costs and customer satisfaction (Mills \& Morris, 1986). The central role of customers in service production is further emphasised by the service-dominant logic (Vargo \& Lusch, 2004), which advocates that customers are the primary creators of value in services and service companies facilitate the process of value creation. In this process of value creation, customers integrate resources to create value (Vargo \& Lusch, 2004). Those resources include company resources and offerings, together with customer skills and knowledge. Furthermore, customers need to have knowledge of how to integrate those resources in order to produce optimal value (Hibbert, Winklhofer \& Temerak, 2012). The service-dominant logic suggests that the role of the service provider is to facilitate value creation with the provision of resources to the customer (Vargo \& Lusch, 2004). In this facilitator role, the service provider needs to provide conditions for customer learning of skills and knowledge in terms of how to integrate production resources (Hibbert et al., 2012).

Following the recognition of the central role of customers in services, researchers have suggested that consumer role clarity is essential for successful service completion (Bowen, 1986; Meuter, Bitner, Ostrom \& Brown, 2005). Role clarity is defined as customers' knowledge of what is expected of them during SST encounters (Meuter et al., 2005). In an SST context, research has found that detailed role clarity and successful completion of self-service gives the consumer a sense of achievement and control and reduces technology anxiety, while poor role clarity can be detrimental, not only for the service that the particular consumer receives, but also for the quality of service received by other customers of the company (Bateson, 1985). Meuter et al.'s (2005) research into SST initial trial by customers confirmed the importance of consumer role clarity as a predictor of SST adoption. Similarly, Kim, Christodoulidou and Brewer (2012) found that role clarity is one of the strongest predictors of customers' likelihood to use SSTs in a hospitality context. Meuter et al. (2005) recommends as an avenue for further research the exploration of the effects of customer socialization on the formation of better role clarity.

Another term which is often used interchangeably with role clarity in SST research is customer self-efficacy (e.g. Oyedele \& Simpson, 2007; Zhao, Mattila \& Tao, 2008; van Beuningen, Ruyter, Wetzels \& Streukens, 2009). Self-efficacy reflects the customer's belief that they have the ability to produce a service as required (van Beuningen et al., 2009). The formation of customer self-efficacy has been recognised as a research gap in SST research by Zhao et al. (2008) and van Beuningen et al. (2009). Zhao et al. (2008) found that customer training by the service organisation increases the customer perceptions of self-efficacy and affects usage intentions. Furthermore, van Beuningen et al. (2009) researched how customers form selfefficacy through information searches online. The study included novice customers and their formation of self-efficacy through online sources of the service company, peers and third party sources (van Beuningen et al., 2009). Zhao et al. (2008) suggested that there are other unexplored sources of building customer self-efficacy, such as providing written instructions and simulations. Furthermore, many SSTs are 
now past their initial adoption, and customers have accumulated experience (Wang, Harris \& Patterson, 2012) which may be transferred to similar SST encounters.

A method for introducing customers to their service production roles is customer socialization, which draws on similar practices like employee organizational socialization (Mills \& Morris, 1986; Goodwin, 1988; Kelley, Donnelly \& Skinner, 1990). Customer socialization includes the acquiring of abilities, values and selfperception needed to perform as a 'partial employee' (Goodwin, 1988). There are a number of tested methods for customer socialization including distributing of service company marketing literature, incorporating cues in the service environment, formal customer introduction to the organization, reinforcement of desired behaviour, and observation of other customers (Kelley et al., 1990). Cues in the design of the service environment can be utilized by companies to indirectly manage customers' participation (Ford \& Bowen, 2003).

With the democratisation of the information on the internet, customer learning is becoming more independent from the sole efforts of the service company (Pires, Staunton \& Rita, 2006). Customer learning has been further facilitated by websites, online forums, frequently asked questions (FAQ) pages and social networks (Temerak, Winklhofer \& Hibbert, 2009). The service-dominant logic in services marketing (Vargo \& Lusch, 2004) suggests the adoption of a customer centric view and recognises the value creating power of customers as self-initiating resource integrators towards achieving their goals. In this light, socialization and training as concepts in customer learning have been criticized by Hibbert et al. (2012) as these concepts imply a company centric view. Hibbert et al. (2012) advocate the 'agentic role' of the customer in self-initiating learning. The democratisation of customer learning necessitates the customer perspective to be studied as the full process of customer learning is not accessible to service provider observations or management (Hibbert et al., 2012). Hibbert et al. (2012) propose that customer learning should be regarded as a self-directed learning process depending on personal factors (e.g. learning autonomy and personal resources), learning environment (e.g. learning resources, learning support and opportunities to learn) and learning trigger events (e.g. expectation of required learning, external and internal drivers, and multiple versus single learning episodes). There appears to be a gap in the knowledge regarding the sources of customer role learning, and how customers respond to different sources in terms of learning outcomes (Temerak et al., 2009; Hibbert et al., 2012). The present research aims to build on Hibbert et al.'s (2012) model by exploring the sources of customer SST role learning. A further contribution is the exploration of other sources of customer role learning in an SST context in addition to training (Zhao et al., 2008) and information sources online (Beuningen et al., 2009).

On the basis of the review of literature on customer learning in services and the arising gaps, the objective of this research is to explore from a customer perspective the sources of customer SST role learning and how customers transform this information into learning outcomes. Similarly to Hibbert et al. (2012) this research adopts the view that SST customers are the central agent in the decision as to which learning sources to consider and how to learn from them. 


\section{Methodology}

This study into customer role learning was part of a larger research project into customer usage of SSTs. The limited knowledge on actual customer usage behaviour during SST encounters (Wang et al., 2012) and the numerous calls for qualitative research (Baron, Patterson \& Harris, 2006; Lin \& Chang, 2011) justified the employment of short interviews as a data collection instrument. This instrument of data collection was suggested as appropriate for gaining of broad understanding of the issues in a marketing area where little prior research is available (Carson, Gilmore, Gronhaug \& Perry, 2001). The short interviews may be applied as a standalone data collection instrument, but with limitations regarding the depth of the gained understandings (Carson et al., 2001). Wang et al. (2012) successfully employed short semi-structured interviews of 10-15 minutes at supermarket check-outs.

The interviews were conducted by the principle researcher with 133 airline passengers in the departure lounge of an international airport. With a view to avoiding any preconceptions, the research included a broad sample in terms of ages, gender, professional backgrounds and education. The average length of an interview was 5-10 minutes, this being a feature of the dynamic nature of the airport environment. The participants were asked to talk about their general SST usage, and were encouraged to discuss examples, or particularly memorable experiences (positive or negative) with an SST. The interviews were transcribed and analysed using an interpretive method of data analysis (Miles \& Huberman, 1994). This method of data analysis is not seeking to uncover laws of causality, but rather to capture the essence of a participant's account and to understand the meaning of actions (Goulding, 2005). The interpretive analysis included reading and re-reading of each transcript until the researchers understood the essence of the participant's views. The following section will present the findings regarding the sources of customer role learning and how customers learned from them.

\section{Findings}

When reflecting on their usage of SSTs, customers often revealed their sources of learning in terms of how to engage with an SST. Those reflections were interpreted by the researchers in view of the way customers employ the various sources to learn their SST usage role. The interpretive analysis revealed six main sources of customer learning namely the SST interface, other customers, company employees, mass media and service environment, negative service outcomes and the customer's workplace. Those sources will be examined below in turn, supported by selected illustrative quotes from the data. The presented quotes are labelled with unique codes that correspond to interview participants. The codes appear after each quote in the following way: (Int.28.M). This identifies interviewee number 28 who was a male participant.

\subsection{The SST Interface}

The SST interface emerged as the major source of customer learning. The SST interface may encourage or discourage customers from engaging with self-service, i.e. 
some may find it complicated. There is an expectation by some customers that the SST interface is the primary communicator of usage instructions. A participant, who had an unsatisfactory experience in trying to purchase printer ink cartridges using the self check-outs in the supermarket, suggested that it was the SST interface which should have informed him to remove the packaging before getting out of the shop: 'I didn't realise the packaging had to be removed before I went out of the shop. So, when I scanned it through, it didn't make it clear to me that it needed to be removed.' (Int.28.M) Customers responded in a variety of ways to the information and instructions on the SST interface. Some customers learned from the interface about the customer skill requirements for participation in the SST encounter. For example, an elderly lady suggested that she has learned to try and complete the booking process as fast as she can: 'I am always afraid because when you are booking tickets online, for security reasons, they only give you a certain amount of time, don't they? You have to do it fairly quickly.' (Int.109.F)

The marketing and advertising on SST interfaces invoked a response on the part of customers by making them more alert and vigilant, because this was sometimes viewed as an attempt by the service provider to sell extra services that they may not need. The following is a participant's comment about an airline's website: 'So, they build the website to entice you into buying all these extra services that you don't need. So, you have to have your wits about you.' (Int.15.M) If there were inconsistencies on the SST interface, some customers even responded by contacting the service provider: I went to the baggage allowance section and it told you any sports equipment can be a maximum of $20 \mathrm{~kg}$. And when I was actually booking the ticket I went into it separately, there was a different clause which said that sports equipment is generally $20 \mathrm{~kg}$, mountain bikes exception is $30 \mathrm{~kg}$... So, I had to ring them. (Int.21.M)

Other customers perceived the SST interface as offering standardized services and learned to contact the service provider to negotiate for further inclusions. Similarly, to the customers who are afraid that they may purchase unwanted extra services, those customers fear that the technology may not give them the best deal, so they double check with a personal agent:

I look up my specification on the computer, ring up Dell, and say this is what I want, and I am talking to a person. And I say: 'Can you do better?', and last time the person at the other end said that they couldn't give me any money off but they doubled the memory. (Int.23.M)

It appears that the SST interface may be a direct source of customer learning through the provided operational instructions, or an indirect source through cues and reminders or stimuli in the design.

\subsection{Other Customers}

Many customers learned aspects of their role during SST encounters by observing other customers' performance. Depending on their observations, some customers concluded that they lack sufficient knowledge and may need to ask for help from more experienced customers, whilst others learned that they may offer help to less experienced friends and family, and indeed, on occasion to strangers. The following quote illustrates how an elderly lady learned that she needs to seek help from other 
customers when engaging with SSTs by observing that other customers are more knowledgeable, willing and able to help her: 'there is always someone around that will help you if you just ask. My age group, really, isn't into a lot of technology.' (Int.109.F). Some customers responded in a more proactive manner by learning from fellow customers. An elderly lady stated: 'I have learned from my grandson, from my children. They showed me and then I try and I am much better than I used to be.' (Int.33.F)

The observation of other customers may not only lead to learning how to operate an SST, but also learn a lead user role in helping and tutoring less knowledgeable customers:

They were struggling with the online check-in kiosk...he was German, himself and his wife and two kids and I helped them check-in. (Int.35.F)

Within the role of helping other customers, some participants learned the finer aspects of judging when their help was needed:

I mean, family is one thing, like my parents would not be great with computers, so I have to book things for them...But I find that if it is somebody I don't know, they are stressing out, you are nearly better off not trying to help them, because they are already highly sensitive... Well, like, you might gage a bit... Some people if they need help, like, they will be throwing up eyes: 'Somebody come help me!' And other people they will just be [expletive] screaming and shouting and, like, you know, if you do go near them, they will be like: 'Get away!' (Int.38.M)

When observing other SST users, customers may judge whether they have the skills and knowledge to help and tutor other customers, or they should be the ones in the 'help-seeker' role. This in turn determines how customers will engage with other customers during SST encounters.

\subsection{Company Employees}

Even though SSTs presuppose no employee involvement, employees were still a source of customer learning. Company employees promoted awareness of the SST option. Furthermore, company employees were often available to assist and teach inexperienced SST customers on-site or over online chat and customer lines. Company employees may be a source of promotion of the SST option, although customers may not respond favourably initially:

Yeah, sometime if you go into the tax office, there is a big queue and they'd say to you: 'Why don't you pay online?' And, you are working here, it's a job for you. So, I find in the tax office, they try get you to pay online. So, I've started to do that now. (Int.116.F)

Company employees may further emphasise the notion that customers are 'on their own' with SSTs, i.e. they have to teach themselves, and it is up to them how they learn to use the SST:

There is a counter beside the ticket machines, so, there are personnel there, but they are often less friendly than the machines, you know. Even though you mightn't know to use the machine, they will just point you. (Int.63.F)

Even when company employees were available for assistance, this was not always perceived as helpful by some novice customers. A participant who was assisted with 
an airport kiosk stated: 'I got the impression like they showed you one time, and you are supposed to remember that forever.' (Int.9.F)

Although the company may train their staff to promote awareness of the SST option and assist inexperienced customers in learning their production role, the learning response was sometimes that of resistance. When employees are present on-site, some customers perceived that as an indication that the service would be delivered for them, rather than being directed to use an SST.

\subsection{Mass media and Service Environment}

Customer learning was also facilitated by mass media stories relating to SSTs. Some customers reacted to media information by incorporating into their role actions which may prevent possible service failures that they have heard about. The general customer observations of the developments in service technology further contributed learning outcomes towards the customer usage role. Some customers, who follow the latest developments in SSTs on the market, may demand those from companies. While others, when observing the general developments in the service landscape and the introduction of more SSTs, felt forced to learn how to use them.

A participant heard in the media about a booking company which closed for business and customers' reservations were not honoured when they arrived at hotels they prebooked. This made the participant wary and he pro-actively sent a confirmation email to a hotel he booked online 'just to be sure, to be sure, to be sure'(Int.101.M).

Some participants displayed knowledge of the service landscape, which resulted in expectations for their SST role. The excerpt below illustrates how this participant's awareness of the service landscape and current developments, enabled this customer to play a consulting role to the company:

I think, you could benefit more if the companies like [name of airline company], who I booked for today, they do an online check-in system. I think, they need to start incorporating it into your phone because everyone has got these smart phones nowadays, and you should be able to use your boarding pass, I find, on your phone instead of printing it off. (Int.79.M)

The learning outcome from observation of the technological developments in services for another participant was that engaging with SSTs is close to compulsory, i.e. customers are obliged to invest the effort into learning how to use them:

I just feel that you have to use it now because everything is more difficult if you have not got your internet... I am forced, as I am older, I felt a bit forced into learning it...And I know the banking, it is going to be, everybody is on the internet now...and you have to, you have to like it, you have to move with the times. (Int.33.F)

SST customers appear to utilise the media stories featuring consequences from SST usage as a learning source to optimise their actions and ensure satisfactory service outcomes. Similarly observing the developments of SSTs in services could convey messages to the customer as to what their role should be.

\subsection{Negative Service Outcomes}


Customer role learning occurred when reflecting on the outcomes from SST encounters. The positive outcomes often served as an affirmation of their existing production role, while negative outcomes had a more dramatic effect on customer role learning. Therefore, the attention here is on negative service incidents and the outcomes for customer learning. The quote below illustrates how an SST failure made this customer realise an element of his role as a customer:

[When] We have been abroad on holiday, any time we use an ATM and we can't get any cash. But normally that's our own fault. Now we make a point of... we send a quick email to the bank to say that we are going abroad. (Int.15.M)

Another participant learned from an SST failure that if customers are given more power to engage in service recovery, this will improve the service. The learning outcome prepared this customer for undertaking a role in recovering service failures, such as in this example of discussing failures of self-service photocopiers in universities:

There is less, you know, self-service stuff for repairing stuff. See you have to call somebody in then and that's labour intensive and time, people don't rely on time. So that's the only thing that I see with, because people could fix printing machines and credit machines easily if there was like step-by-step stuff. (Int.121.M)

Another customer had a different reaction to SST failures. The experience that SSTs often fail, and assistance from an employee is needed, paradoxically has made this participant use the SST option only if an employee is around, because 'I am trying to do something, [it] is going to go wrong, and I am going to waste time trying to find somebody to get my change out for me.' (Int.22.F) Alternatively, the notion that there may be a failure when using SSTs has taught one participant that he should not rely on SSTs for last minute transactions: 'Sometimes when you are relying on technology for last minute and it does not work, you've got to pay the price.' (Int.3.M) Similarly, another participant (Int.36.F) learned to be more vigilant when booking online after getting 'caught out' once to pay double what they expected for a room because of confusion with price per room and price per person.

Some SST customers have learned another lesson from their experiences, i.e. that if something goes wrong they should expect frustration when trying to resolve the problem:

I think if we had a downside to all this, it's simply you often can't speak to people. There is no, you can't find a telephone line, or if you do find a telephone line, you go through a number of menus on the telephone. Ahh, and that's, I think frustrating, very frustrating. Or alternatively, if you do get through, and it's someone who has difficulty understanding what you are saying or is not familiar with the goods, or then they say we'll email you back and that doesn't happen. (Int.73.M)

The above quotes suggest that SST failure incidents are very important learning experiences for customers. Some customers may learn how to prevent failures, while others learned how to deal and cope with negative service outcomes when they occur.

\subsection{The Workplace}


Another source of customer learning was their professional occupation, especially if it was connected with using technologies. The technology usage at their workplace could contribute towards the technical skill required to use SSTs:

When I was younger, I used to work in a supermarket, so I know how to use all the [self-service check-outs]...so... I can do it fast. (Int.117.F)

A participant, who indicated that she worked as a teacher commented:

I was a teacher. I retired a couple of years ago and it was all technology in the school, I had to teach with technology and I found it very difficult to teach. I had to ask for a lot of advice from the younger teachers, because I had to practice it. (Int.33.F)

Alternatively, participants who worked in IT already knew a lot about how SSTs should function which introduced an element of judgement to their SST customer role:

But I get frustrated if you are looking for more information, and since I work in technology, I have no patience for any self-service online systems, whether it is bank, car rental, whatever it is if they frustrate me at all, too many clicks, you know, any of that. (Int.50.M)

I used to be in the technology industry, so when I see something that I think is ridiculous or redundant, I would usually shoot them up a quick note saying... this stuff doesn't work right, you should do it this other way. (Int.58.M)

The technological proficiency that customers developed at their workplace contributed to the technological skills to operate an SST. For customers, whose jobs required higher levels of technological knowledge, it was observed that there was an element of judging the SST service process as part of their role.

\section{Discussion}

The contribution of this research is to add to the theoretical knowledge about the process of customer role learning in SST encounters. The objective was to explore the sources of SST customer role learning and how customers learn their production role from them. It is important to emphasize that channels of customer socialization should not be treated interchangeably with sources of customer learning. As Hibbert et al. (2012, p.2) suggested contemporary customers should not be regarded as passive recipients of company training and communications, but rather as independent 'agentic actors' who are exposed to various sources of information.

In line with prior research (Kelley et al., 1990; van Beuningen et al., 2009) this study found that the information provided by the service company on the SST interface is a major source of customer learning. While most participants had little problem with following the SST instructions, some customers have learned to be vigilant for any stimuli for purchasing additional services that they may mistakenly fall for. Furthermore, the customer 'agentic role' during learning, as suggested by Hibbert et al. (2012), is revealed by customers not just learning passively from the instructions, but also applying their previous knowledge and experience in shaping their role. Our findings suggest that companies should be extra careful how the webpage design is perceived by their customers, and that customer feedback should be sought and valued. 
There is still an existing problem that customers appear to socialise themselves in line with the preconception that SSTs are for the younger, technologically proficient customers. It may be reasonable to conclude that SST interfaces have not yet reached an accessible design and delivery process acceptable to all users. Some SST usage challenges include unclear instructions and the speed at which customers need to complete the transaction. The perception of irreversibility of customer mistakes when using SSTs, together with difficult access to customer service, may create anxiety in the customer role. This anxiety may even turn some customers into passive SST users through asking other customers to operate the SST for them. Fellow customers have been suggested as instrumental in socialising novelty service users (Kelley et al., 1990), or as a source of customer role learning (Mills \& Morris, 1986; Temerak et al., 2009), and this paper advances the knowledge on customer learning from this source by exploring how fellow customers may affect the role learning process. When observing, or interacting with other customers, SST users may decide that they possess insufficient skills to complete an SST transaction and leave or ask another customer to do that for them. Another group of customers learned how to undertake the role of a 'student' and a 'teacher' during SST encounters. Their interaction helped the 'student' to acquire more skills towards operating SSTs, and the 'teacher' learned how to optimise the tutoring.

Company employees, although a good source of SST awareness promotion and learning, were not always perceived as benevolent in their position. If customers were directed to an SST, when they were already at the personal service counters, they often rebelled and judged the employee service negatively. Furthermore, although Zhao et al.'s (2008) research confirmed that training increases SST usage, our findings suggest that training customers by onsite employees may not always provide the desired positive usage results. Therefore, service providers should be very strategic when trying to promote the SST option, and very patient in training customers. For example, the SST option could be suggested to the customer for their next transaction and the employee may explain the procedure if the customer displays interest.

While mass media has been identified as a provider of customer role learning information (Mills \& Morris, 1986; Hibbert et al., 2012), this paper introduces the general service environment as another learning source. The service environment includes all services and service delivery channels available to customers. Much of the customer learning has happened before they approached the specific company's SST. This learning has been accumulated from previous usage of other SSTs, or from stories in the media and from peer experiences. Furthermore, companies should be vigilant and use campaigns to combat strong media stories which may have a detrimental effect on SST usage. For example, the ash crisis from 2010 turned some people away from booking trips online because it highlighted the risks of the online channel. The directly experienced negative outcomes from previous SST encounters were found to have a learning value for customers. Wang et al. (2012) found that service failures may be tolerated by customers to an extent, but ultimately they made customers avoid the SST option. The present research adds to the debate on the effects of previous SST usage with the finding that negative service outcomes may have a learning effect on customer participation. While negative outcomes may have a 
positive learning effect, companies should not rely on this source to teach their customers, because frequent failures make customers avoid the SST.

Finally, this research introduces the customer's workplace as another source of technical skill learning in operating SSTs. This source of customer learning, while independent from direct service company efforts, is a very valuable source as often customers may be forced to learn skills at the workplace which otherwise they may avoid during service encounters. It appears that even though customers have resorted to many sources of role learning, some of which are independent of the direct service firm's control, i.e. other customers, the workplace, media stories and the service landscape, the most desired learning source for both customers and service providers is the well-built SST interface. So even though contemporary service customers have the option of learning from independent sources, companies should implement the knowledge from this research and aim to preserve their facilitating role when it comes to customer learning.

\section{Conclusion}

In order to contribute more knowledge towards understanding how customers learn their SST production role, this research explored the sources of customer role learning from a customer perspective. The findings from the short interviews with airline passengers revealed six main sources of customer learning, i.e. the SST interface, other customers, company employees, mass media and the service environment, negative service outcomes and the customer's work environment. Those sources were analysed in terms of the various ways in which customers may interpret the information and transform it into a role learning outcome. Those findings contribute towards the understanding of customer learning from a customer's perspective and aim to provide insights for service providers towards creating better strategies for customer training and socialization. Although many SST customers proactively learn from various information sources, our findings reveal that there could be mixed learning outcomes in terms of production role learning. This suggests that service providers should carefully monitor the customer learning process and tailor-make their marketing communications to facilitate the successful performance of all customer segments.

When applying the findings from this research, its limitations should be considered. While the interviewed participants represented a diversity of demographic and social backgrounds, the data was collected from a convenience sample of airline travellers in one location. Therefore, variations in findings may be observed in different settings and with other participants. Further limitation of this research constitutes the insufficient depth in questioning during the short interviews. The aim of this research was to gain initial understanding of customer SST behavioural patterns and should be followed by a more comprehensive data collection instrument, such as in-depth interviews or focus groups. Furthermore, it was beyond the scope of this research to investigate the interplay between the various learning sources and the effect of customer differences on the way those sources are employed for role learning. Such an investigation may provide useful information for marketers in understanding how different learning sources may be interpreted by different customer segments. 


\section{References}

Baron, S., Patterson, A. \& Harris, K. (2006). Beyond Technology Acceptance: Understanding Consumer Practice, International Journal of Service Industry Management, 17(2): 111-35.

Bateson, J. (1985). Self-Service Customer: an Exploratory Study, Journal of Retailing, 61(3): $49-76$

Bowen, D. (1986). Managing Customers as Human Resources in Service Organizations, Human Resource Management, 25(3): 371-83.

Carson, D., Gilmore, A., Perry, C. \& Gronhaug, K. (2001). Qualitative Marketing Research, London: Sage.

Castro, D., Atkinson, R. \& Ezell, S. (2010). Embracing the Self-Service Economy, The Information Technology and Innovation Foundation, April 2010.

Ford, R. \& Bowen, J. (2003.) Getting Guests to Work for You, Journal of Foodservice Business Research, 6(3): 37-53.

Goodwin, C. (1988). 'I Can Do It Myself: Training the Service Consumer to Contribute to Service Productivity, The Journal of Services Marketing, 2(4): 71-8.

Goulding, C. (2005). Grounded Theory, Ethnography and Phenomenology: A Comparative Analysis of Three Qualitative Strategies for Marketing Research, European Journal of Marketing, 39(3/4): 294-308.

Hibbert, S., Winklhofer, H. \& Temerak, M. (2012). Customers as Resource Integrators: Towards a Model of Customer Learning, Journal of Service Research, Early site.

Kelley, S., Donnelly, J. \& Skinner, S. (1990). Customer Participation in Service Production and Delivery, Journal of Retailing, 66(3): 315-35.

Kim, J., Christodoulidou, N. \& Brewer, P. (2012). Impact of Individual Differences and Consumers' Readiness on Likelihood of Using Self-Service Technologies at Hospitality Settings, Journal of Hospitality and Tourism Research, 26(1): 85-114.

Lin, J. \& Chang, H. (2011). The Role of Technology Readiness in Self-Service Technology Acceptance, Managing Service Quality, 21(4): 424-44.

Meuter, M., Bitner, M., Ostrom, A. \& Brown, S. (2005). Choosing Among Alternative Service Delivery Modes: An Investigation of Customer Trial of Self-Service Technologies, Journal of Marketing, 69(April): 61-83.

Meuter, M., Ostrom, A., Roundtree, R. \& Bitner, M. (2000). Self-Service Technologies: Understanding Customer Satisfaction with Technology-Based Service Encounters, Journal of Marketing, 64(July): 50-64.

Miles, M. \& Huberman, M. (1994). Qualitative Data Analysis, Second Edition, Thousand Oaks, CA: Sage.

Mills, P. \& Morris, J. (1986). Clients as 'Partial' Employees of Service Organizations: Role Development in Client Participation, Academy of Management Review, 11(4): 726-35.

Oyedele, A. \& Simpson, P. (2007). An Empirical Investigation of Consumer Control

Factors on Intention to Use Selected Self-Service Technologies, International Journal of Service Industry Management, 18(3): 287-306.

Pires, G., Stanton, J. \& Rita, P. (2006). The Internet, Consumer Empowerment and Marketing Strategies, European Journal of Marketing, 40(9/10): 936-49.

Temerak, M., Winklhofer, H. \& Hibbert, S. (2009). Managing Customer Participation Through Customer Education, The Naples Forum on Service: Service-Dominant Logic, Service Science, and Network Theory, Capri, June 16-19, 2009.

Van Beuningen, J., Ruyter, K., Wetzels, M. \& Streukens, S. (2009). Customer SelfEfficacy in Technology-Based Self-Service, Journal of Service Research, 11(4): 407-28.

Vargo, S. \& Lusch, R. (2004). Evolving to a New Dominant Logic for Marketing, Journal of Marketing, 68(January): 1-17. 
Walker, R. \& Johnson, L. (2006). Why Consumers Use and Do Not Use TechnologyEnabled Services, Journal of Services Marketing, 20(2): 125-35.

Wang, C., Harris, J. \& Patterson, P. (2012). Customer Choice of Self-Service Technology: The Role of Situational Influences and Past Experience, Journal of Service Management, 23(1): 54-78.

Zhao, M. \& Dholakia, R. (2009). A Multi-Attribute Model of Web Site Interactivity and Consumer Satisfaction, An Application of the Kano Model, Managing Service Quality, 19(3): 286-307. 